\title{
Validity and reliability of the Portuguese version of the modified Migraine Disability Assessment
}

\author{
Pedro L. Ferreira ${ }^{1 *} \mathbb{D}$, Isabel Luzeiro ${ }^{2}$, Margarida Lopes ${ }^{3}$, André Jorge $^{4}$, Bruno Silva ${ }^{4}$ and Lara Ferreira ${ }^{5}$
}

\begin{abstract}
Background: Migraine Disability Assessment Scale (MIDAS) is a useful tool to measure headache-related disability. Modified MIDAS with 4-week recall period reduces recall bias and improves accuracy of the results. This study aimed at validating mMIDAS in Portuguese.

Methods: Studied population consisted of adult migraine patients attending a headache outpatient clinic. Reliability was assessed by internal consistency and reproducibility in a 3-week test-retest. Content validity was evaluated by two expert panels. Construct validity was tested by comparing mMIDAS-P index in socioeconomic and clinical patient groups and scale unidimensionality was evidenced by factor analysis. Criterion validity was tested using EQ-5D-5L and HADS.

Results: Ninety-two patients, $88 \%$ female, mean age of 44 years, participated. They had, in average, 9.7 headache days in previous month, pain averaging $7.5 / 10$. About $69.9 \%$ were on a migraine prophylactic treatment, and $42.4 \%$ had severe disability; 29.4 and 13.0\% showed, respectively, moderate/severe anxiety and depression. Content validity showed that mMIDAS-P is simple and clinically useful. It did not show to be determined by patient's sociodemographic characteristics and it was correlated with depression scale and EQ-5D-5L. Test-retest demonstrated high reproductive reliability and good internal consistency.
\end{abstract}

Conclusion: mMIDAS-P is valid and reliable. We strongly recommend it for clinical and research use.

Keywords: Patient reported outcomes, Quality of life, Migraine, mMIDAS-P, Productivity, Disability

\section{Background}

Migraine is an episodic primary headache syndrome, the most common type of headache worldwide, affecting 1 out of 10 people [1]. Although pain is the most commonly reported symptom, migraine is associated with nonpainful symptomatology, including aura, prodrome and postdrome symptoms, which can be as disabling as pain itself, with all its spectrum of manifestations. Migraine is a highly disabling condition, with impact at the social,

\footnotetext{
* Correspondence: pedrof@fe.uc.pt

${ }^{1}$ Centre for Health Studies and Research of University of Coimbra/Centre for Innovative Biomedicine and Biotechnology, Faculty of Economics of University of Coimbra, Coimbra, Portugal

Full list of author information is available at the end of the article
}

family and professional levels, profoundly affecting patient quality of life (QoL). In Portugal, headache disorders are the third most disabling health problem with over 2 million people suffering from migraine in the country; its prevalence is $18.1 \%$, all ages [2].

A useful tool to measure this disability is the Migraine Disability Assessment Scale (MIDAS), developed after 1998 by Stewart and colleagues [3-6], aimed to improve the communication between care providers and migraine patients. It was developed from the Headache Impact Questionnaire (GImQ) to measure headache severity, excluding the pain dimension, to obtain an easier way to compute a global score [7]. MIDAS has been largely used 
to evaluate the impact of migraine and has been proven simple to use, consistent, highly reliable, and correlating well with physicians' clinical judgments in several studies, not only in USA and UK English [6, 8], but also in many other languages. Among such languages, we may cite, by alphabetic order, Arabic [9], Chinese [10], French [11], German [12], Greek [13], Hindi [14], Italian [15], Japanese [16], Malay [17], Persian [18], Portuguese-Brazil [19], Spanish [20], Thay [21], and Turkish [22]. MIDAS also proved to be useful to identify adequate treatments and to stratify them based on the level of patient disability $[9,23]$.

Recently, a minor modification was performed in the original MIDAS questionnaire: the recall time was changed from 3-months to 4-weeks [24]. This modification was expected to reduce recall bias and improve accuracy of the results, and termed the questionnaire mMIDAS.

Portuguese is the ninth most spoken language in the world, with 234 million speakers and, although MIDAS had previously been translated into European Portuguese, it had not yet been validated in this language. The authors endeavoured to apply this translated version of MIDAS on a migraine Portuguese population, to evaluate the reliability, internal consistency, and validity of the Portuguese mMIDAS (mMIDAS-P) questionnaire.

\section{Methods}

\section{Study design}

This study aimed at validating mMIDAS and studying the QoL of a sample of migraine patients. Under no circumstances, it interfered with health professionals' decisions concerning the most appropriate medical approach for each patient. Before data collection, all participants filled in a written informed consent and this study received the approval from the Ethics Commission of the Coimbra University Hospital.

\section{Participants}

The study was conducted between September 25th and December 6 th $^{\text {th }} 2019$ at the Neurology Department of Coimbra University Hospital. Studied population consisted of consecutive adult patients observed in a headache outpatient clinic. These were evaluated and included in the study by a clinician if older than 18 years, with chronic or episodic migraine, with ability to give consent to participate in the study, and if able to read and write Portuguese for self-completion of questionnaires. Excluded were unstable patients or with uncontrolled symptoms and considered by clinicians as unable to fill the measures, cognitively affected, and those who could not understand Portuguese. The questionnaire was completed during the consultation.

\section{Measures}

Besides mMIDAS, we applied a generic QoL instrument (EQ-5D-5L), two questions about satisfaction with life and social support, a specific psychological instrument to measure anxiety and depression (HADS); and a short socioeconomic set of questions.

mMIDAS is a self-administered questionnaire that contains seven questions about the headache a patient had in the previous month [3-6]. The first five questions assess the impact of migraine on three domains of daily activity: two questions for paid work or schoolwork, two questions for household work, and one question for family, social and leisure activities. The two questions for each of the first two groups assess, respectively, the number of days off due to headache, and the number of days in which the productivity was reduced by half or more.

The sixth and seventh additional questions, for the clinicians' benefit, count the frequency of headache days in the previous month, and the average intensity of the headache attacks, in a 0 (no pain at all) to 10 (pain as bad as it can be) scale.

mMIDAS index is derived from the sum of the answers on the first five questions. This score defines patients in four categories of headache disability: little/ none disability if the score is between 0 and 5; mild disability if between 6 and 10; moderate disability if between 11 and 20; and severe disability if greater than 20 [4-6].

The original version of MIDAS is available on the National Headache Foundation website and is presented in the Supplementary file 1. A first Portuguese nonvalidated translation of mMIDAS has been provided by the author through Mapi Research Trust (see Supplementary file 2). Therefore, before implementing this measure, we decided to validate its contents by clinical reviews with Portuguese neurologists and by cognitive debriefings with patients. We also tested its reliability, as well as its construct and criterion validity.

EQ-5D-5L is a short generic QoL preference measure that allows generating an index representing the value assigned to an individual's health status. It was developed by the EuroQoL Group in 1987 and it is currently composed of a descriptive system and a visual analogue scale (VAS). The descriptive system represents health in five dimensions: mobility, self-care, usual activities, pain/ discomfort and anxiety/depression. Each of these dimensions has five associated severity levels and a weighted scoring procedure to create an EQ-5D-5L index score [25].

VAS has the appearance of a thermometer (vertical line with about $20 \mathrm{~cm}$ ), whose scale ranges from 0 (worst imaginable health status) to 100 (best imaginable health status), with the individual having directly to mark what value s/he attributes to her/his current health status. 
In this study, we have used the Portuguese version approved by the EuroQoL Group [26].

To measure the satisfaction with life we asked the patient whether s/he agreed with the sentence "I am happy with my life", in a 5-point scale from 'completely disagree' to 'completely agree'. The social support question refers to the expected number of individuals the patient would be able to ask for help in case of need.

The Hospital Anxiety and Depression Scale (HADS) is composed by 14 items, grouped in two subscales separately scored and measuring, respectively, anxiety and depression. Each item is answered in a 4-point Likert scale from 0 to 3 and it takes approximately $2-5 \mathrm{~min}$ to be completed [27]. For each subscale, a score between 0 and 7 is considered normal, between 8 and 10 mild, between 11 and 14 moderate and between 15 and 21 severe.

In this study, we have used the Portuguese validated version [28].

The sociodemographic information included gender, age, marital status, years of education and employment status.

We also asked physicians to provide clinical information about patient's health status. This included age of migraine diagnosis, time of follow-up, headache frequency and characteristics, use of prophylactic treatment and types of drugs used in the past to prevent headache, as well as acute headache treatment. At last, we also collected information on patients' comorbidities.

Statistically, one first decision we had to make was related to the use of non-parametric statistics, depending on whether mMIDAS-P index follows a normal distribution.

Therefore, we firstly raised the following hypothesis:

\section{$\mathrm{H}_{1}$ : The distribution of mMIDAS-P index is normal}

\section{Reliability}

Reliability was assessed through intertemporal stability and internal consistency. To test the intertemporal stability, we used the intraclass correlation coefficient (ICC). To avoid recall bias, eligible patients filled mMIDAS-P in two consecutive moments 3 weeks apart, the same interval used by the authors in their original validation study $[4,5]$, as well as in some other countries. As defended by Koo, an ICC score lower than 0.50 corresponds to a weak correlation, between 0.50 and 0.75 to a moderate correlation, between 0.75 to 0.90 to a good correlation and a score higher than 0.90 corresponds to an excellent correlation [29]. We also looked at the correlation factor between each item of mMIDAS-P and the whole scale.

The internal consistency was measured by the Cronbach's alpha coefficient, where recommended values should be between 0.70 and 0.90 [30]. For this study, two hypotheses were raised:
$\mathrm{H}_{2}$ : mMIDAS-P shows good intertemporal stability.

$\mathrm{H}_{3}$ : mMIDAS-P shows good internal consistency.

\section{Validity}

We followed the internationally defined methodology to validate QoL measures. Under this framework, we tested content, construct and criterion validity [30]. As a translated Portuguese version already existed, we started by asking for a clinical revision performed by two neurologists, and a cognitive debriefing with 10 patients to guarantee the content validity, i.e., the relevance of the mMIDAS-P items. We formulated the following hypothesis:

$\mathrm{H}_{4}$ : mMIDAS-P is well accepted by clinicians and patients, not showing ambiguities, redundancies or lack of contents.

Construct validity, addressing the theoretical concepts behind the measurement instrument, encompassed the structural validity and hypothesis testing [30]. Structural validity was tested by exploratory factor analysis based on principal components estimates, having previously applied the sampling adequacy through the measure of sample adequacy Kaiser-Meyer-Olkin (KMO) and by Bartlett's test of sphericity. A KMO smaller than 0.50, between 0.50 and 0.60 or between 0.60 and 0.70 is considered, respectively, unacceptable, poor or fair. Scores between 0.70 and 0.80 , between 0.80 and 0.90 or higher than 0.90 are considered, respectively, average, good or very good [31]. Bartlett sphericity test should have an associated significance of $<0.001$. For the selection of the number of factors, we followed the Kaizer criterion for eigenvalues greater than 1 .

For the hypothesis testing, we formulated several hypotheses with known-groups or subsamples based on sociodemographic and clinical variables. Should mMIDAS$\mathrm{P}$ index be normally distributed, Student's t-test was to be used for two independent variables and ANOVA for more than two independent variables. Should mMIDAS-P index be not normally distributed, the nonparametric Kolmogorov-Smirnov and Kruskal-Wallis tests were to be used. The following hypotheses were then defined:

$\mathrm{H}_{5}$ : The structure of mMIDAS-P maintains the unidimensionality.

$\mathrm{H}_{6}$ : mMIDAS-P scores are dependent from sociodemographic variables.

$\mathrm{H}_{7}$ : mMIDAS-P scores are dependent from clinical variables.

Criterion validity was assessed by comparing mMIDAS$\mathrm{P}$ index with the ones obtained by HADS and EQ-5D-5L, considered as gold standard references. We also compared 
mMIDAS-P index with the results from the two additional questions of mMIDAS questionnaire. The statistical rule used was mainly based on Spearman's correlation coefficient, but Pearson's correlation was also computed to detect the role of possible outliers. As defined by Cohen, correlations smaller than 0.30 are considered weak, between 0.30 and 0.50 are moderate, and higher than 0.50 are considered strong [32].

By comparing mMIDAS-P with HADS and EQ-5D-5L, we expected to detect similarities and differences between dimensions, such as depression [33] and migraine pain [34]. By comparing with the sixth and the seventh questions, we expected a positive correlation with headache frequency, measured by the number of days with headache, and with the headache intensity, measured by the average intensity of these headaches. Therefore, we tested the following hypotheses:

$\mathrm{H}_{8}$ : mMIDAS-P index correlates positively with the number of days with headache.

$\mathrm{H}_{9}$ : mMIDAS-P index correlates positively with the average intensity of headache.

$\mathrm{H}_{10}$ : mMIDAS-P index correlates with HADS dimensions anxiety and depression.

$\mathrm{H}_{11}$ : mMIDAS-P index correlates with both EQ-5D-5L index and VAS.

\section{Results}

\section{Sample}

The sample was composed by 92 patients. Socioeconomic characteristics and impact on QoL of patients are presented in Table 1 . Table 2 shows some of the clinical headache characteristics.

Ninety-two patients, $88 \%$ female, with a mean age of 44 years participated. A large percentage was married or lived together (66.3\%), were employed (73.9\%), and a fourth had less than 9 years of education. This sample is representative to all eligible migraine patients seen by the Neurology Department of Coimbra University Hospital.

In what concerns the measure of disability due to migraine, $68.5 \%$ of the patients suffered from moderate to severe disability and the median score was 16 . Migraine frequency in previous month was 9.78 times (median $=6$ ). In a scale from 0 to 10 , the average intensity of headache was 7.5 (median $=8$ ).

In general, the QoL self-assessed by patients was reported as 82.0 from EQ-5D-5L index, and 73.4 from VAS. Patients also showed normal to mild anxiety (median 8) and normal depression (median 6). Moreover, $10.9 \%$ had severe anxiety and $4.3 \%$ were severely depressed.

Concerning the sentence 'I am happy with my life', $52.2 \%$ agreed and $22.9 \%$ disagreed. In the loneliness question, $63.1 \%$ declared having at least three persons to ask for help, if needed.

Regarding the clinical variables, patients had their migraine diagnosis when they were about 31 years of age, had a follow-up of about 3.8 years, and had had in average 8.9 headaches in previous month. About $70 \%$ were submitted to a prophylactic treatment, the majority of them with antiepileptic (54.3\%) and antidepressant drugs $(52.2 \%)$. In crisis, $97.8 \%$ of patients followed an acute treatment, especially using analgesics $(91.3 \%)$ and tryptans $(47.8 \%)$. In general, the large majority of patients $(79.1 \%)$ did not report any other comorbidity.

As mentioned before, we firstly tested whether the variable mMIDAS-P index was normally distributed $\left(\mathrm{H}_{1}\right)$. Following the results of the one-sample KolmogorovSmirnov test (test statistic $=0.225 ; p<0.001$ ), we decided to reject the null hypothesis, i.e., we assumed a non-normality of the mMIDAS-P index.

\section{Reliability}

Table 3 reveals the ICC scores obtained from a 3-week test-retest on 30 patients, without any dropout. It shows an overall mMIDAS-P index highly reliable $(\mathrm{ICC}=$ $0.903)$, with partial scores between good (0.891) and excellent (0.997).

Cronbach's alpha indicator of internal consistency was 0.793, within the recommended set of values. Therefore, we did not reject hypotheses $\mathrm{H}_{2}$ and $\mathrm{H}_{3}$.

Furthermore, the correlations between mMIDAS-P index and each of the five components revealed scores from moderate (mMIDAS5) to good (mMIDAS4).

\section{Validity}

To assess semantic and cultural validity of mMIDAS-P version provided by Mapi, we asked two neurologists to perform clinical reviews. Very few and minor changes were proposed and immediately accepted by the research team. On the other hand, two cognitive debriefing meetings were performed with 10 migraine patients (two men; eight women), who filled mMIDAS-P in $2.9 \pm$ $1.5 \mathrm{~min}$ (median $=2.0 \mathrm{~min}$ ). Patients did not evidence difficulties in understanding the measure nor did they find redundancies or ambiguities in the questions. In addition, the scores were very easy to be computed. We did not reject $\mathrm{H}_{4}$.

To test construct validity and the factor structure of mMIDAS-P index, exploratory factor analysis was applied to the database of 92 responses. This analysis allowed us to guarantee the unidimensionality defined by the author, with $55.6 \%$ of explained variance and the factor loadings as presented in Table 4. The KMO test obtained was 0.733 and the Bartlett sphericity test had an associated significance $(<0.001)$, which allowed us to pursue with the analysis. 
Table 1 Sociodemographic characteristics of the sample $(n=92)$

\begin{tabular}{|c|c|c|c|}
\hline Variable & Value & $\mathrm{N}$ & $\%$ \\
\hline \multirow[t]{2}{*}{ Gender } & Female & 81 & 88.0 \\
\hline & Male & 11 & 12.0 \\
\hline \multirow[t]{6}{*}{ Age (years) } & 19-39 & 31 & 33.7 \\
\hline & $40-49$ & 33 & 35.9 \\
\hline & $50-78$ & 28 & 30.4 \\
\hline & Min- max & 19-78 & \\
\hline & Mean \pm standard deviation & $44.0 \pm 11.9$ & \\
\hline & Median & 44 & \\
\hline \multirow[t]{3}{*}{ Marital status } & Single & 19 & 20.7 \\
\hline & Married or living together & 61 & 66.3 \\
\hline & Widowed/divorced/separated & 12 & 13.1 \\
\hline \multirow[t]{4}{*}{ Years of education } & $0-4$ & 4 & 4.4 \\
\hline & $5-9$ & 19 & 20.6 \\
\hline & $10-12$ & 30 & 32.6 \\
\hline & $>12$ & 39 & 42.4 \\
\hline \multirow[t]{3}{*}{ Employment status } & Employed & 68 & 73.9 \\
\hline & Unemployed/student & 14 & 15.2 \\
\hline & Other & 10 & 10.9 \\
\hline \multirow[t]{9}{*}{ mMIDAS index } & Min - max & $0-126$ & \\
\hline & Mean \pm standard deviation & $28.5 \pm 29.7$ & \\
\hline & 25th percentile & 7 & \\
\hline & $50^{\text {th }}$ percentile & 16 & \\
\hline & $75^{\text {th }}$ percentile & 38 & \\
\hline & Little or no disability (0-5) & 15 & 16.3 \\
\hline & Mild disability (6-10) & 14 & 15.2 \\
\hline & Moderate disability (11-20) & 24 & 26.1 \\
\hline & Severe disability (> 20) & 39 & 42.4 \\
\hline \multirow[t]{3}{*}{ Migraine frequency (mMIDAS-6) } & Min-max & $0-30$ & \\
\hline & Mean \pm standard deviation & $9.78 \pm 8.9$ & \\
\hline & Median & 6 & \\
\hline \multirow[t]{3}{*}{ How painful were the headaches, 0-10 (mMIDAS-7) } & Min-max & $0-10$ & \\
\hline & Mean \pm standard deviation & $7.5 \pm 1.9$ & \\
\hline & Median & 8 & \\
\hline \multirow[t]{2}{*}{ Quality of life (EQ-5D-5L - Index) } & Min-max & $5-100$ & \\
\hline & Mean \pm standard deviation & $82.0 \pm 19.7$ & \\
\hline \multirow[t]{2}{*}{ Quality of life (EQ-5D-5L - VAS) } & Min-max & $30-100$ & \\
\hline & Mean \pm standard deviation & $73.4 \pm 18.2$ & \\
\hline \multirow[t]{7}{*}{ Anxiety (HADS) } & Normal (0-7) & 40 & 43.5 \\
\hline & Mild (8-10) & 25 & 27.1 \\
\hline & Moderate (11-14) & 17 & 18.5 \\
\hline & Severe (15-21) & 10 & 10.9 \\
\hline & Min-max & $0-18$ & \\
\hline & Mean \pm standard deviation & $8.0 \pm 3.9$ & \\
\hline & Median & 8 & \\
\hline
\end{tabular}


Table 1 Sociodemographic characteristics of the sample $(n=92)$ (Continued)

\begin{tabular}{|c|c|c|c|}
\hline Variable & Value & $\mathrm{N}$ & $\%$ \\
\hline \multirow[t]{7}{*}{ Depression (HADS) } & Normal (0-7) & 57 & 62.0 \\
\hline & Mild (8-10) & 23 & 25.0 \\
\hline & Moderate (11-14) & 8 & 8.7 \\
\hline & Severe (15-21) & 4 & 4.3 \\
\hline & Min-max & $0-18$ & \\
\hline & Mean \pm standard deviation & $6.2 \pm 4.2$ & \\
\hline & Median & 6 & \\
\hline \multirow[t]{5}{*}{ I am happy with my life } & Totally disagree & 3 & 3.2 \\
\hline & Disagree & 18 & 19.6 \\
\hline & Neutral & 23 & 25.0 \\
\hline & Agree & 38 & 41.3 \\
\hline & Totally agree & 10 & 10.9 \\
\hline \multirow[t]{4}{*}{ Number of people to ask for help } & None & 5 & 5.4 \\
\hline & $1-2$ persons & 29 & 31.5 \\
\hline & $3-5$ persons & 39 & 42.4 \\
\hline & 6 or more persons & 19 & 20.7 \\
\hline
\end{tabular}

Even when including all seven mMIDAS questions in the factor analysis, the unidimensionality could not be rejected; however, question mMIDAS7 had a very low communality (0.196) and the total percent of variance decreased a little bit to $52.6 \%$. We concluded that it is better to maintain only the five first questions as part of the total mMIDAS-P score $\left(\mathrm{H}_{5}\right)$.

Construct validity was tested by comparing mMIDAS$\mathrm{P}$ index with patients' sociodemographic characteristics $\left(\mathrm{H}_{6}\right)$. As presented in Table 5, mMIDAS-P did not show to be determined by patient's sociodemographic gender, age or education variables.

However, single patients tend to have a lighter impact of their migraine.

In what concerns the clinical variables age of migraine diagnosis, time of follow-up, previous prophylactic treatment, and other comorbidities, mMIDAS-P also showed not to be determined by any level of these variables $\left(\mathrm{H}_{7}\right)$.

To test criterion validity, we correlated mMIDAS-P index with the number of days with headache [mMIDAS6]. The result of Spearman's correlation was 0.793 $(p<0.01)$, evidencing a positive significant correlation $\left(\mathrm{H}_{8}\right)$. We also compared mMIDAS-P index with the average intensity of headaches (mMIDAS7). In our sample, the correlation between these two variables was $0.300(p=0.004)$, also evidencing a positive significant correlation $\left(\mathrm{H}_{9}\right)$ (Table 6).

The EQ-5D-5L dimensions with higher correlation scores with mMIDAS-P were pain/discomfort (0.422; $p<0.001)$ and anxiety/depression (0.422; $p<0.001)$. mMIDAS-P also showed to be correlated with HADS depression scale $(0.568 ; p<0.001)\left(\mathrm{H}_{10}\right)$ and with both EQ-5D-5L index $(-0.474 ; p<0.001)$ and VAS $(-0.442$; $p<0.001)\left(\mathrm{H}_{11}\right)$.

\section{Discussion}

mMIDAS index is based on answers about disability associated to migraine, in previous month. This disability is measured in terms of missed days of activity and days with reduced productivity, considering productivity at work or school, household work and non-work (family, social, leisure) activity. With this measure, we assume that a very severe headache may result in missing more than one of these activities, and so, a single day of headache may correspond to more than one point in the index $[6,10]$. On the other hand, results show that mMIDAS-P index was skewed distributed towards high values, as the 25th, 50th and 75th percentiles were, respectively, 5 (little/mild disability), 16 (moderate disability) and 38 (severe disability).

Sociodemographic variables in our study were similar to those in other MIDAS validations: higher prevalence of females, patients in the 40-49 age group, employed, with a better QoL, with mild anxiety, normal depression, and an average of about 10 episodes of headache in previous month, with an average severity of 7.5 in a $0-10$ scale. In what concerns happiness with life, more than half of the patients declared being satisfied and, in general, with enough social support if needed $[4,5]$.

We found evidence that migraine patients are more willing to miss household work than family, social or 
Table 2 Clinical characteristics of the sample $(n=92)$

\begin{tabular}{|c|c|c|c|}
\hline Variable & Value & $\mathbf{N}$ & $\%$ \\
\hline \multirow[t]{5}{*}{ Age of migraine diagnosis (years) } & Min-max & $2-76$ & \\
\hline & Mean \pm standard deviation & $31.2 \pm 14.7$ & \\
\hline & $<20$ & 27 & 29.3 \\
\hline & $21-39$ & 39 & 42.4 \\
\hline & $\geq 40$ & 26 & 28.3 \\
\hline \multirow[t]{5}{*}{ Time on consultation (years) } & Min-max & $0-37$ & \\
\hline & Mean \pm standard deviation & $3.8 \pm 5.6$ & \\
\hline & $<1$ & 36 & 39.2 \\
\hline & $1-3$ & 27 & 29.3 \\
\hline & $\geq 4$ & 29 & 31.5 \\
\hline \multirow[t]{2}{*}{ Frequency of headaches in previous month } & Min-max & $0-30$ & \\
\hline & Mean \pm standard deviation & $8.9 \pm 4.5$ & \\
\hline \multirow[t]{4}{*}{ Prophylactic treatment } & Now, continued & 41 & 49.4 \\
\hline & Now, not previously & 17 & 20.5 \\
\hline & Not now, but previously yes & 18 & 21.7 \\
\hline & Never & 7 & 8.4 \\
\hline \multirow[t]{2}{*}{ Previous prophylactic treatment } & Yes & 59 & 71.1 \\
\hline & No & 24 & 28.9 \\
\hline \multirow[t]{9}{*}{ Drugs prescribed } & Antiepileptic & 50 & 54.3 \\
\hline & Antidepressant & 48 & 52.2 \\
\hline & Beta-Blockers & 34 & 36.9 \\
\hline & Botulinum Toxin A & 1 & 12.0 \\
\hline & Calcium Blockers & 7 & 7.6 \\
\hline & Non-Steroidal anti-Inflammatory & 4 & 1.4 \\
\hline & Neuromodulation Devices & 1 & 1.1 \\
\hline & Invasive Treatments & 1 & 1.1 \\
\hline & Other & 10 & 10.9 \\
\hline \multirow[t]{2}{*}{ Acute treatment for migraine } & Yes & 89 & 97.8 \\
\hline & No & 2 & 2.2 \\
\hline \multirow[t]{7}{*}{ Acute therapeutics usually followed } & Analgesics & 84 & 91.3 \\
\hline & Trypanoes & 44 & 47.8 \\
\hline & Antiemetics & 15 & 16.3 \\
\hline & Opioids & 6 & 6.5 \\
\hline & Ergotaminicos & 5 & 5.4 \\
\hline & Corticosteroids & 2 & 2.2 \\
\hline & Other & 1 & 1.1 \\
\hline \multirow[t]{2}{*}{ Other comorbidities } & Yes & 18 & 20.9 \\
\hline & No & 68 & 79.1 \\
\hline
\end{tabular}

leisure activities, being the employment or school work the one they are less willing to miss. This can probably be explained by the fact that, because paid or school work are considered as more stable activities, they are more easily remembered by patients, as also hypothesized by Hung and colleagues [10]. Also, the number of days in which the activities are reduced by half or more were always higher than the number of full days missed, which may inform us that some patients still maintain their work even suffering from pain [10]. 
Table 3 ICC for test-retest study

\begin{tabular}{|c|c|c|c|c|c|c|}
\hline \multirow[t]{2}{*}{ Because of headaches, during last month, } & \multicolumn{2}{|c|}{ Test $(n=92)$} & \multicolumn{3}{|c|}{ Retest $(n=30)$} & \multirow{2}{*}{$\begin{array}{l}\text { Correlation } \\
\text { with MIDAS-P }\end{array}$} \\
\hline & Mean & Median & Mean & Median & ICC & \\
\hline [1] \# missed days of work or school & 2.07 & 0.0 & 1.60 & 0.0 & $0.997^{2}$ & $0.697^{1}$ \\
\hline [2] \# days with productivity reduced by half or more & 7.90 & 5.0 & 8.50 & 4.5 & $0.957^{2}$ & $0.828^{1}$ \\
\hline [3] \# missed days of household work & 5.64 & 2.0 & 9.03 & 3.0 & $0.981^{2}$ & $0.749^{1}$ \\
\hline [4] \# days with household work productivity reduced by half or more & 9.47 & 5.5 & 9.60 & 6.0 & $0.950^{2}$ & $0.853^{1}$ \\
\hline [5] \# missed days of family, social or leisure activities & 3.54 & 2.0 & 2.53 & 1.0 & $0.891^{2}$ & $0.564^{1}$ \\
\hline MIDAS- $P$ index & 28.5 & 16.0 & 29.2 & 20.0 & $0.903^{2}$ & \\
\hline [6] \# days with headache & 9.78 & 6.0 & 10.5 & 10.0 & $0.832^{2}$ & \\
\hline [7] In a 0-10 scale, on average, how painful were these headaches & 7.49 & 8.0 & 8.07 & 8.0 & $0.780^{2}$ & \\
\hline
\end{tabular}

${ }^{1} p<0.01^{2} p<0.001$

The average mMIDAS-P index was 28.5 and the range varied from 0 to 126 . Regarding the question mMIDAS7 addressing the average intensity of headache pain, we obtained (Table 3) a lower reliability (ICC $=0.780$ ). However, we did not feel any need to modify the question as happened in Hindi [14] and in Turkish [22] versions. Likewise, we decided to maintain mMIDAS6 as it was, and not use intervals instead of fixed number of days, as proposed by the French version [11].

Even recognizing that older studies used Pearson's or Spearman's correlations to test intertemporal stability and newer studies used ICC, the reliability scores obtained in this study (ICC $=0.821$ and alpha $=0.793$ ) are comparable with the ones reported by other countries' studies. Table 7 presents the reliability scores of validations in other languages.

Also, the correlation factors between each mMIDAS-P item and the whole scale gave correlations between 0.564 (moderate) and 0.853 (good), all of them significant $(p<0.01)$. Internal consistency Cronbach's alpha is very comparable with the values obtained in the original version and from other languages.

In what concerns validity, mMIDAS-P results are, in general, comparable with other validation studies, even with different methodology. UK and USA [5], Japan [16] and Thailand [21], compared their results with 90-day diary measures patients were supposed to fill; some

Table 4 Factor analysis scores

\begin{tabular}{ll}
\hline Because of headaches, during last month, & Factor loadings \\
\hline [1] \# missed days of work or school & 0.738 \\
[2] \# days with productivity reduced by half or more & 0.821 \\
[3] \# missed days of household work & 0.746 \\
[4] \# days with household work productivity reduced & 0.839 \\
by half or more & \\
[5] \# missed days of family, social or leisure activities & 0.548 \\
\hline
\end{tabular}

studies did it with HIT-6 as Hindi version [14], and some others with SF-12, SF-36 or RAND-36, as the Persian [18] or Greek [13] versions. However, as far as we know, our version is the first one comparing MIDAS scores with psychological indicators and preferencebased QoL measures.

The construct validity confirmed the unidimensionality of mMIDAS-P, as in the original version and the results from Shaik [17] and Mourad [9]. The Spanish version [20], however, in a population of young university students, presented a 2-factor structure, one composed by engagement in activities (items 1, 3 and 5), and the other corresponding to the performance at work (items 2 and 4).

Comparing mMIDAS-P index with scores obtained in known-groups, we found no significant differences among the several levels of patients' characteristics, namely gender, age and education, as well as clinical variables age of migraine diagnosis, time of follow-up, previous prophylactic treatment, and other comorbidities.

Criterion validity was tested by comparing the mMIDAS-P index with the two extra mMIDAS items, with self-reported anxiety and depression from HADS and with QoL scores provided by EQ-5D-5L. Portuguese mMIDAS index showed a positive and significant correlation with both extra items, with anxiety index, especially with pain/discomfort and anxiety/depression of EQ-5D-5L. It should be noted that mMIDAS focusses on symptoms related with migraine.

One limitation of this study may derive from the sample size. We collected data from 92 migraine patients, very close from our initial goal of having 100 patients. However, considering the COSMIN checklist [35] and the non-existed missing values, our sample size may be considered very good for the measurement properties we used to validate mMIDAS.

A second possible limitation may lie in the patients' characteristics of our sample. These patients were recruited from an ambulatory department's migraine 
Table 5 mMIDAS scores for different levels of sociodemographic and clinical variables

\begin{tabular}{|c|c|c|c|c|c|c|c|c|}
\hline \multirow[t]{2}{*}{ Variable } & \multirow[t]{2}{*}{ Value } & \multirow[t]{2}{*}{$\mathbf{n}$} & \multirow[t]{2}{*}{ Mean } & \multirow{2}{*}{$\begin{array}{l}\text { Comparisons } \\
\text { Test Statistic (sig) }\end{array}$} & \multicolumn{4}{|c|}{ mMIDAS Grade Disability } \\
\hline & & & & & None/little/mild & moderate & severe & $x^{2}$ (sig) \\
\hline \multirow[t]{2}{*}{ Gender $^{a}$} & Female & 81 & 28.7 & 0.940 & $86.2 \%$ & $79.2 \%$ & $94.9 \%$ & $3.617(p=0.164)$ \\
\hline & Male & 11 & 25.5 & $(p=0.340)$ & $13.8 \%$ & $20.8 \%$ & $5.1 \%$ & \\
\hline \multirow[t]{3}{*}{ Age $^{b}$} & $19-39$ & 31 & 20.3 & 3.202 & $44.8 \%$ & $37.5 \%$ & $23.1 \%$ & $5.335(p=0.255)$ \\
\hline & $40-49$ & 33 & 33.8 & $(p=0.202)$ & $34.5 \%$ & $25.0 \%$ & $43.6 \%$ & \\
\hline & $50-78$ & 28 & 31.1 & & $20.7 \%$ & $37.5 \%$ & $33.3 \%$ & \\
\hline \multirow[t]{2}{*}{ Marital status ${ }^{a}$} & Single & 19 & 13.7 & 1.666 & $31.0 \%$ & $33.3 \%$ & $5.1 \%$ & $9.998(p=0.007)$ \\
\hline & Non-single & 73 & 32.3 & $(p=0.008)$ & $69.0 \%$ & $66.7 \%$ & $94.9 \%$ & \\
\hline \multirow[t]{2}{*}{ Years of education ${ }^{a}$} & $\leq 12$ years & 53 & 24.0 & 1.236 & $72.4 \%$ & $54.2 \%$ & $48.7 \%$ & $3.982(0.137)$ \\
\hline & $>12$ years & 39 & 34.9 & $(p=0.094)$ & $27.6 \%$ & $45.8 \%$ & $51.3 \%$ & \\
\hline \multirow[t]{3}{*}{ Age of migraine diagnosis (years) } & $\leq 20$ & 27 & 21.0 & 1.025 & $34.5 \%$ & $25.0 \%$ & $28.2 \%$ & $1.095(p=0.895)$ \\
\hline & $21-39$ & 39 & 28.8 & $(p=0.599)$ & $37.9 \%$ & $50.0 \%$ & $41.0 \%$ & \\
\hline & $\geq 40$ & 26 & 35.8 & & $27.6 \%$ & $25.0 \%$ & $30.8 \%$ & \\
\hline \multirow[t]{3}{*}{ Time of follow-up (years) ${ }^{b}$} & $<1$ & 36 & 32.3 & 0.578 & $34.5 \%$ & $37.5 \%$ & $43.6 \%$ & $1.914(p=0.752)$ \\
\hline & $1-3$ & 27 & 26.4 & $(p=0.749)$ & $31.0 \%$ & $37.5 \%$ & $23.1 \%$ & \\
\hline & $\geq 4$ & 29 & 25.6 & & $34.5 \%$ & $25.0 \%$ & $33.3 \%$ & \\
\hline \multirow[t]{2}{*}{ Previous prophylactic treatment ${ }^{\mathrm{a}}$} & Yes & 59 & 32.0 & 0.896 & $64.0 \%$ & $61.9 \%$ & 81.1 & $3.270(p=0.195)$ \\
\hline & No & 24 & 24.2 & $(p=0.399)$ & $36.0 \%$ & $38.1 \%$ & 18.9 & \\
\hline \multirow[t]{2}{*}{ Other comorbidities $^{a}$} & Yes & 18 & 25.8 & 0.512 & $22.2 \%$ & $17.4 \%$ & $22.2 \%$ & $0.238(p=0.888)$ \\
\hline & No & 68 & 29.2 & $(p=0.956)$ & $77.8 \%$ & $82.6 \%$ & $77.8 \%$ & \\
\hline
\end{tabular}

Independent-samples Kolmogorov-Smirnov test; ${ }^{b}$ Independent-samples Kruskal-Wallis test

consultation of a general hospital. Considering the mMIDAS index, circa than one third of them had, at most, a mild migraine. We are confident that our range is representative from the actual distribution of migraine patients from the general population.

A third issue we should address is that, when we compare mMIDAS scores with those obtained from more generic measures we may run the risk of comparing with a wider range of symptoms. However, migraine, when exists, usually dominates all other sources of discomfort, and so, we think that the comparisons made were appropriate.

\section{Conclusion}

This study supports the use of the Portuguese version of mMIDAS (mMIDAS-P) is a valid and reliable instrument to evaluate disability caused by migraine.

Table 6 Correlation between mMIDAS scores, QoL variables and headache characteristics

\begin{tabular}{lllr}
\hline & Variable & Pearson $\mathbf{r}$ & Spearman rho \\
\hline Headaches & \# days with headache & $0.836(p<0.001)$ & $0.792(p<0.001)$ \\
& Average intensity & $0.346(p=0.001)$ & $0.300(p=0.004)$ \\
HADS & Anxiety & $0.181(p=0.084)$ & $0.160(p=0.128)$ \\
& Depression & $0.507(p<0.001)$ & $0.339(p=0.001)$ \\
EQ-5D-5L & Mobility & $0.183(p=0.080)$ & $0.104(p=0.326)$ \\
& Self-care & $0.306(p=0.003)$ & $0.157(p=0.136)$ \\
& Usual activities & $0.648(p<0.001)$ & $0.512(p<0.001)$ \\
& Pain/discomfort & $0.507(p<0.001)$ & $0.408(p<0.001)$ \\
& Anxiety/depression & $0.537(p<0.001)$ & $0.422(p<0.001)$ \\
& Index & $-0.675(p<0.001)$ & $-0.474(p<0.001)$ \\
VAS & $-0.457(p<0.001)$ & $-0.442(p<0.001)$ \\
\hline
\end{tabular}


Table 7 Comparable reliability score with the original and some MIDAS versions

\begin{tabular}{lllll}
\hline Country & Language & Source & Test-retest reproducibility & Internal consistency \\
\hline Portugal & Portuguese & 14 & $0.90^{\mathrm{b}}$ & 0.80 \\
Lebanon & Arabic & 15 & $0.99^{\mathrm{b}}$ & 0.81 \\
Taiwan & Chinese & $0.79^{\mathrm{a}}$ & 0.67 \\
USA & English & $0.80^{\mathrm{a}}$ & 0.76 \\
UK & English & 8 & $0.83^{\mathrm{a}}$ & 0.73 \\
Canada & French & 16 & $0.84^{\mathrm{b}}$ & $\mathrm{NA}$ \\
Switzerland & German & 17 & $0.99^{\mathrm{b}}$ & 0.69 \\
Greece & Greek & 18 & $0.82^{\mathrm{b}}$ & 0.71 \\
India & Hindi & $0.94^{\mathrm{a}}$ & $>0.90$ \\
Italia & Italian & 20 & $0.81^{\mathrm{a}}$ & 0.74 \\
Japan & Japanese & $0.83^{\mathrm{a}}$ & 0.82 \\
Malaysia & Malay & 21 & $0.87^{\mathrm{a}}$ & 0.84 \\
Iran & Persian & 22 & $0.71^{\mathrm{a}}$ & 0.80 \\
Brasil & Portuguese & 23 & $0.77^{\mathrm{a}}$ & 0.70 \\
Spain & Spanish & 24 & $0.81^{\mathrm{b}}$ & 0.80 \\
Thailand & Thai & 25 & $0.76^{\mathrm{b}}$ & $0.68^{\mathrm{a}}$ \\
Turkey & Turkish & 26 & & 0.91
\end{tabular}

aPearson's/Spearman's correlation coefficient; ${ }^{b}$ Interclass correlation coefficient NA not available in the paper

Our results are consistent with the original version as well as with other validation studies.

It is suitable for use in clinical practice as a decision aid tool to improve health care strategies centered on migraine patients. It allows the assessment of the impact on disability and improves the relationship and the communication between physician and patient [36]. It has also shown to be well accepted by migraine patients.

\section{Supplementary Information}

The online version contains supplementary material available at https://doi. org/10.1186/s12883-021-02085-z.

Additional file 1.

Additional file 2.

\section{Abbreviations}

EQ-5D-5L: Eurogol 5 dimensions 5 levels; GImQ: Headache Impact

Questionnaire; HADS: Hospital Anxiety and Depression Scale; ICC: Intraclass Correlation Coefficient; KMO: Kaiser-Meyer-Olkin; MIDAS: Migraine Disability Assessment Scale; mMIDAS: Modified Migraine Disability Assessment Scale; mMIDAS-P: Portuguese mMIDAS; QoL: Quality of life; VAS: Visual Analogue Scale

\section{Acknowledgements}

The authors thank Novartis for their support. Particular thanks are due to patients who, in a very willing way, accepted to participate in this study. The authors are also thankful to Mapi Research for their cooperation in granting the permission for MIDAS validation.

\section{Headings}

- mMIDAS-P is a valid and reliable instrument to evaluate disability caused by migraine.
- Results from the Portuguese version are consistent with the original version as well as with other validation studies.

- mMIDAS-P is suitable for use in clinical practice as a decision aid tool to improve health care strategies cantered on migraine patients.

- We strongly recommend its use in clinical practice and in research to measure the impact of migraine in patients' QoL.

\section{Authors' contributions}

PLF and LNF contributed to the study conceptualization and participated in its design and coordination, together with IL. IL also coordinated the data collection performed by ML AJ and BS. PLF drafted the manuscript and all authors have read and approved the content of the final version.

\section{Funding}

This project was funded by a research grant from Novartis Farma. The authors were not in any way influenced by this funding. This was only used for logistic purposes. CEISUC/CIBB is funded by national funds through FCT Foundation for Science and Technology, I.P., under the Multiannual Financing of R\&D Units 2020-2023.

\section{Availability of data and materials}

The dataset used and/or analysed during the current study is available from the corresponding author on reasonable request.

Ethics approval and consent to participate

The Directive Board and the Ethics Commission of the Coimbra University Hospital (Process no. CHUC-011-19) approved the study. Patients provided written informed consent for all aspects of the study.

Consent for publication

Not applicable.

\section{Competing interests}

The authors declare that they have no competing interests.

\section{Author details}

${ }^{1}$ Centre for Health Studies and Research of University of Coimbra/Centre for Innovative Biomedicine and Biotechnology, Faculty of Economics of 
University of Coimbra, Coimbra, Portugal. ${ }^{2}$ Neurology Department of Coimbra University Hospital Centre, Faculty of Medicine of University of Coimbra, Coimbra, Portugal. ${ }^{3}$ Neurology Department of Braga Hospital, Braga, Portugal. ${ }^{4}$ Neurology Department of Coimbra University Hospital Centre, Coimbra, Portugal. ${ }^{5}$ Centre for Health Studies and Research of University of Coimbra/Centre for Innovative Biomedicine and Biotechnology, University of Algarve, School of Management, Hospitality and Tourism, Faro, Portugal.

Received: 28 August 2020 Accepted: 31 January 2021

Published online: 06 February 2021

\section{References}

1. Woldeamanuel YW, Cowan RP. Migraine affects 1 in 10 people worldwide featuring recent rise: A systematic review and meta-analysis of communitybased studies involving 6 million participants. J Neurol Sci. 2017;372:307-15.

2. GBD 2016 Headache Collaborators. Global, Regional, and National Burden of Migraine and Tension-Type Headache, 1990-2016: A Systematic Analysis for the Global Burden of Disease Study 2016. Lancet Neurol. 2018;17(11):954-76.

3. Lipton RB, Goadby PJ, Sawyer JPC, Blakeborough P, Stewart WF. Migraine: diagnosis and assessment of disability. Rev Contemp Pharmacother. 2000; 11:63-73.

4. Stewart WF, Lipton R, Kolodner K, Liberman J, Sawyer J. Reliability of the migraine disability assessment score in a population- based sample of headache sufferers. Cephalalgia. 1999a;19(2):107-14.

5. Stewart WF, Lipton RB, Whyte J, Dowson A, Kolodner K, Liberman JN, et al. An international study to assess reliability of the migraine disability assessment (MIDAS) score. Neurology. 1999b;53(5):988-94.

6. Stewart WF, Lipton RB, Kolodner KB, Sawyer J, Lee C, Liberman JN. Validity of the migraine disability assessment (MIDAS) score in comparison to a diary-based measure in a population sample of migraine sufferers. Pain. 2000;88(1):41-52.

7. Stewart WF, Lipton RB, Simon D, Von Korff M, Liberman J. Reliability of an illness severity measure for headache in a population sample of migraine suffers. Cephalagia. 1999c;18:44-51.

8. Lipton RB, Stewart WF, Sawyer J, Edmeads JG. Clinical utility of an instrument assessing migraine disability: the migraine disability assessment (MIDAS) questionnaire. Headache. 2001;41(9):854-61.

9. Mourad D, Hajj A, Hallit S, Ghossoub M, Khabbaz L. Validation of the Arabic version of the migraine disability assessment scale among Lebanese patients with migraine. J Oral Facial Pain Headache. 2019;33(1):47-53.

10. Hung P-H, Fuh J-L, Wang S-J. Validity, reliability and application of the Taiwan version of the migraine disability assessment questionnaire. J Formos Med Assoc. 2006;105(7):563-8.

11. Magnoux E, Freeman MA, Zlotnik G. MIDAS and HIT-6 French translation: reliability and correlation between tests. Cephalalgia. 2007;28:26-34.

12. Benz T, Lehmann S, Gantenbein AR, Sandor PS, Stewart WF, Elfering A, Aeschlimann AG. Angst F. Health Qual Life Outcomes. 2018;16:42.

13. Oikonomidi T, Vikelis M, Artemiadis A, Chrousos G, Darviri C. Reliability and validity of the Greek migraine disability assessment (MIDAS) questionnaire. Pharmacoecon Open. 2018;2:77-85.

14. Juyal R, Verma R, Garg RK, Shukla R, Agarwal A, Singh MK. Reliability and validity of Hindi translation of the migraine disability assessment and headache impact test-6 questionnaires. Ann Indian Acad Neurol. 2010;13(4): 276-83.

15. D'Amico D, Mosconi P, Genco S, Usai S, Prudenzano AM, Grazzi L, Leone M, Puca FM, Bussone G. The migraine disability assessment (MIDAS) questionnaire: translation and reliability of the Italian version. Cephalalgia. 2001;21(10):947-52.

16. ligaya M, Sakai F, Kolodner KB, Lipton RB, Stewart WF. Reliability and validity of the Japanese migraine disability assessment (MIDAS) questionnaire. Headache. 2003;43(4):343-52.

17. Shaik MM, Hassan NB, Tan HL, Gan SH. The migraine disability assessment (MIDAS) questionnaire: translation, validation and reliability of Bahasa Melayu version. J Headache Pain. 2014;15(Suppl 1):D56.

18. Zandifar A, Asgari F, Haghdoost F, Masjedi SS, Manouchehri N, Banihashemi M, Ghorbani A, Najafi MR, Saadatnia M, Lipton RB. Reliability and validity of the migraine disability assessment scale among migraine and tension type headache in Iranian patients. Biomed Res Int. 2014;2014:978064.
19. Fragoso YD. MIDAS (migraine disability assessment): a valuable tool for work-site identification of migraine in workers in Brazil. Sao Paulo Med J. 2002;120(4):118-21.

20. Rodríguez-Almagro D, Achalandabaso A, Rus A, Obrero-Gaitán E, ZagalazAnula N, Lomas-Vega R. Validation of the Spanish version of the migraine disability assessment questionnaire (MIDAS) in university students with migraine. BMC Neurol. 2020;20(67):1-7.

21. Seethong P, Nimmannit A, Chaisewikul R, Prayoonwiwat N, Chotinaiwattarakul W. Reliability and validity of migraine disability assessment questionnaire-Thai version (Thai-MIDAS). J Med Assoc Thail. 2013;96(Suppl 2):S29-38.

22. Ertaş M, Siva A, Dalkara T, Uzuner N, Dora B, Inan L, İiman F, Sarica Y, Selçuki D, Şirin H, Oğuzhanoğlu A, Irkeç C, Özmenoğlu M, Özbenli T, Öztürk M, Saip S, Neyal M, Zarifoğlu M. Turkish MIDAS group. Validity and reliability of the Turkish migraine disability assessment (MIDAS) questionnaire. Headache. 2004;44(8):786-93.

23. El Hasnaoui A, Doble A, Gaudin AF. Perception de l'impact de la migraine par le patient: Les outils de mesure. CNS Drugs. 2006;20(SUPPL. 1):24-36.

24. Buse DC, Lipton RB, Hallström Y, Reuter U, Tepper SJ, Zhang F, Sapra S, Picard H, Mikol DD, Lenz RA. Migraine-related disability, impact, and healthrelated quality of life among patients with episodic migraine receiving preventive treatment with Erenumab. Cephalalgia. 2018;38(10):1622-31.

25. Devlin N, Shah K, Feng Y, Mulhern B, van Hout B. Valuing health-related quality of life: an EQ-5D-5L value set for England. Health Econ. 2017;27:1-16.

26. Ferreira PL, Antunes P, Ferreira LN, Pereira LN, Ramos-Goñi LM. A hybrid modelling approach for eliciting health states preferences: the Portuguese EQ-5D-5L value set. Qual Life Res. 2019;28(12):3163-75.

27. Snaith RP. The hospital anxiety and depression scale. Health Qual Life Outcomes. 2003;1:29.

28. Pais-Ribeiro J, Silva I, Ferreira T, Martins A, Meneses R, Baltar M. Validation study of a Portuguese version of the hospital anxiety and depression scale. Psychol Health Med. 2007;12:2,225-37.

29. Koo TK, Li MY. A guideline of selecting and reporting intraclass correlation coefficients for reliability research. J Chiropr Med. 2016;15(2):155-63.

30. Terwee CB, Bot SD, de Boer MR, van der Windt DA, Knol DL, Dekker J, Bouter LM, de Vet HC. Quality criteria were proposed for measurement properties of health status questionnaires. J Clin Epidemiol. 2007:60(1):34-42.

31. Lisboa JV, Augusto MG, Ferreira PL. Estatística aplicada à gestão. Porto: Vida Económica; 2012

32. Cohen J. Statistical power analysis for the behavioural sciences. New York: Lawrence Erlbaum Associates; 1988.

33. Seng EK, Buse DC, Klepper JE, Mayson SJ, Grinberg AS, Grosberg BM, Pavlovic JM, Robbins MS, Vollbracht SE, Lipton RB. Psychological factors associated with chronic migraine and severe migraine-related disability: an observational study in a tertiary headache center. Headache. 2017;57(4):593-604.

34. Kim SY, Park SP. The role of headache chronicity among predictors contributing to quality of life in patients with migraine: a hospital-based study. J Headache Pain. 2014;15:68.

35. Mokkink, L.B., Prinsen, C.A.C., Patrick, D.L., Alonso, J., Bouter, L.M., de Vet, H.C. W., \& Terwee, C.B. (2019). COSMIN Study Design checklist for Patientreported outcome measurement instruments. https://www.cosmin.nl/wpcontent/uploads/COSMIN-study-designing-checklist_final.pdf.

36. Edmeads J, Láinez JM, Brandes JL, Schoenen J, Freitag F. Potential of the migraine disability assessment questionnaire as a public health initiative and in clinical practice. Neurology. 2001;56(suppl 1):S29-34.

\section{Publisher's Note}

Springer Nature remains neutral with regard to jurisdictional claims in published maps and institutional affiliations. 